\title{
MODELLING AND DESIGN OF TECHNOLOGICAL SCHEMES OF UNDERGROUND DEVELOPMENT OF IRON ORE DEPOSITS AT THE INCREASE OF THE DIFFICULTY OF THE CONDITIONS OF THEIR FUNCTIONING
}

\author{
Popov S.O. \\ Doctor of Sciences (Engineering), professor, Department of \\ Automation, Computer Science and Technology, Kryvyi Rih \\ National University, Ukraine \\ Ishchenko M.O. \\ Ph.D. (Engineering), associae professor, Department of Com- \\ puter Systems and Networks, Kryvyi Rih National University, \\ Ukraine

\section{Ishchenko L.F.} \\ Ph.D. (Economics), Kryvyi Rih college, National Aviation University \\ Kryvyi Rih, Ukraine

\section{Kolosovskyi D.} \\ Assistant of the Department of Economics, Organization and \\ Management of Enterprises, Kryvyi Rih National University, Ukraine

\begin{abstract}
The article is devoted to solving a complex problem that arises in the process of preparation for the development of reserves of iron ores underground, in the conditions of great depths of development and difficult economic conditions of operation of iron ore mining enterprises. This problem concerns the development of reserves of mining sites of iron ore deposits and consists in the need to select and put into practice the most costeffective design solutions of structures and technological schemes of extractive blocks, which represent the main production facilities for the extraction of ore. The solution to this problem requires the development of methodology, methods and specialized tools for modelling and designing the designs of technological schemes for the development of block reserves, which would allow choosing and profoundly justified and the most economical such solutions at the systemic level of underground mining. To solve this problem, the authors have developed and tested a system of computer simulation and design of the process of mining the reserves of extractive blocks, in a methodological basis and the concept of which is based systematic object-oriented
\end{abstract}


approach to modelling and design. The algorithm of modelling of technological and logical schemes of working out of stocks of blocks, the procedure of development and application of technical and economic passports of elements of structures of blocks, from which the variants of technological schemes of working out of their stocks are formed and the technical and economic characteristics of realization of these schemes are developed. The system of economic estimation of efficiency of working out of reserves of blocks is also developed. A promising direction for the development of this system is the expansion of its software for more detailed modelling of block elements and their technological schemes, expansion of the database of technical and economic passports of elements of block development schemes and development of graph analytics subsystem of block design support, which provides a significant amount of data for economic and mathematical modelling of block designs and technological schemes of working out their reserves.

Keywords: system, object-oriented approach, computer simulation, flow diagram, underground development.

1. Introduction. At present, underground mining of rich iron ore deposits is one of the bases for the functioning and further development of Ukraine's mining and metallurgical complex. With the use of this method of development, up to $20-25 \%$ of commodity iron ore products of Ukraine are produced. Its raw material base is represented by large reserves of rich hematite ores, well-known in the bowels of Ukraine (the confirmed volume of which is 1.4 billion tons and the forecast reserves exceed 3.0 billion tons). The iron content of the ores of this different species reaches 58-66\%, which makes it possible to use them for metallurgical processing without enrichment and makes them a valuable raw material resource [1,2].

However, the conditions for the deposit and mining of reserves of rich iron ores in Ukraine are characterized by increased complexity, namely: a large depth of distribution of deposits, up to $5.0-7.0 \mathrm{~km}$, currently their reserves are being developed at depths of $1.4-1.5 \mathrm{~km}$. The iron ore mines of Ukraine are the deepest mines for the extraction of this type of raw materials in the world and have the following features: deposits of rich iron ores are characterized by significant power fluctuations $(20.0 \div 150.0 \mathrm{~m})$; deposits do not have clear contours, which requires their special contouring at the stage of geological exploration by methods of economic and mathematical 
modeling; deposits have complex morphology (internal structure), sharp fluctuations and anisotropy of the physical properties of ores; there are severe restrictions on the permissible magnitudes of anthropogenic disturbance of subsoil by their specific geological structure and terrestrial surface in the presence of natural, industrial and social objects on the surface, as they are not subject to wear and tear [3].

All this significantly complicates the development and extremely and negatively affects the very possibility of its implementation and economic results of development.

The prolonged use of underground mining of rich iron ores in Ukraine, which has been going on for over 120 years, has allowed accumulating a large number of various technical and technological solutions that provide both the possibility of their development in these conditions and the economic feasibility of development [4]. These solutions are: technological schemes of development; construction of extractive blocks; Means of mechanization of mining operations; schemes for the discovery of deposits, floors, preparation of ore bodies, cutting and refining of ore, construction of elements of extractive units and methods of performing various types of miningrelated to the extraction of ore and support its implementation [5].

Instead, in a market economy, with its fierce competition for the economic and quality characteristics of commodity iron ore products, it is necessary to ensure not only the technical feasibility and its economic feasibility of development in difficult conditions, but also to achieve its highest economic efficiency. However, the mere use of these solutions does not yet guarantee the achievement of this level of efficiency. This aspect is explained by the fact that the economic results of the implementation of these decisions depend not only on the fundamental ideas underlying it but also determined by the level of their technological, parametric and organizational consistency in the integrated production and technological scheme of the mine under specific geological and mining conditions and mining reserves, as well as the specific economic conditions in which each underground mining enterprise operates [6].

The choice of such solutions and the determination of their effectiveness are carried out at one of the most important stages in the process of preparation for development, namely, the stage of 
designing mining blocks, which represent the main production objects of mining enterprises [7].

The choice of a complex of such solutions and the formation of high-performance technological schemes for them for specific conditions of development is an urgent problem.

This problem can be solved only by detailed economic and mathematical modeling of the production and technological system of mining the reserves of extractive blocks in the structure and dynamics of the operation of the mining enterprise. These dynamics are extremely uneven (rapid change in the parameters of the block and the process of its development in stages) in the life cycle of construction and operation of the mining block. This cycle begins from the moment the ore reserves are discovered in the depths of the mine field and the determination of its characteristics (volume, quality, conditions of occurrence) until the production of commercial iron ore products from the initial mass. This life cycle is multi-stage and complex in structure.

Such modeling is a complex and time-consuming process. The design and modeling of the construction and operation of mining sites are performed by specialized design departments of iron ore enterprises at the systemic level of mining.

Thus, in the field of underground mining of iron ore deposits, there is a serious and complex problem, which consists in the need to select and put into practice the optimal design solutions for the implementation of ore mining in specific mining and economic conditions based on modeling the development process for the full structure of production technological system of the mining enterprise.

A considerable number of domestic and foreign scientists and specialists dealt with the development of methods and tools for modeling and designing the process of development of mining blocks for the conditions of iron ore mining, namely: Malakhov G.M., Faustov G.T., Stupnik M.I., Korzh V.A., Kucheryavenko I.A., Martynov V.K., Fedko M.B., Pluzhnik Y.A., Baranov A.O., Khavzor L.B., Levinson A.A. and a number of others. At the same time, it should be noted that the works of these authors were mainly aimed at developing methods and software for solving local problems of only certain nodes of internal technological schemes of mining blocks without considering them as elements of the general 
production and technological system of the mine, ie not at the systemic level of production. The purpose of the article is to develop theoretical foundations and software for modeling and designing the main production facilities of iron ore mines that would consider these facilities at the systemic level of production of the mining enterprise.

2. Formal problem statement.The above problem can only be solved by solving a number of the following problems:

- development of technical and economic models of underground mining and technological objects with high detail of their structural and technological schemes;

- ensuring high accuracy of determination of the parameters calculated on these models;

- a correct economic evaluation of the options of design solutions that are considered and modeled to select the most effective of them;

- determination of conformity of actual final technical and economic results of the development of reserves of extractive blocks with their design values.

It is necessary to wash that the solution of all these tasks is difficult enough. This is since the mining blocks represent production objects, which are characterized by: the large size, complexity of structures and technology of working out their reserves, the complexity of the underground conditions of their construction and operation.

To give an idea of these blocks and the specifics of their work in Fig. In Fig. 1 shows a diagram of the design of the extractive block, the stock of which is worked out by the system of open space development. This variant of the development system is widely used in the iron ore mines of Ukraine. more than 2000 development systems are being developed for the mining of ore deposits, which are being implemented in mining units. The iron ore mines of Ukraine use more than 50 such options [8]. The choice of the optimal variant of the development system according to the technical and economic criteria for the efficiency of their work for the conditions of each particular excavation site is carried out by performing technical and economic modeling of a number of their variants, which is a complex task of increased complexity. 
The mining block is an underground mining and technological structure, which has the following basic elements: 1 - extraction section within which the mining block is created (in the simultaneous operation of such sections at the mine may be from 4 to 20 , and also 2 - 4 sections are spare ); 2 - recoil floor screed (provides access from the shaft of the mines to the ore deposit; 3 - surface ortho (access from the screed to the sites of cleaning ore extraction); 4- running / economic lifting ortho (provides ventilation of the block and access to drilling sites); 5 drill bit; 6-section of explosive wells; 7-extraction chamber; 8-ceiling over the chamber (the stock of the ceiling is spent after the ore is extracted from the chamber; 9-between the chamber whole (delimits the camera from the adjacent previously used block, the whole of the stock is spent together with the ceiling); 10production of the extracted ore from the chamber.

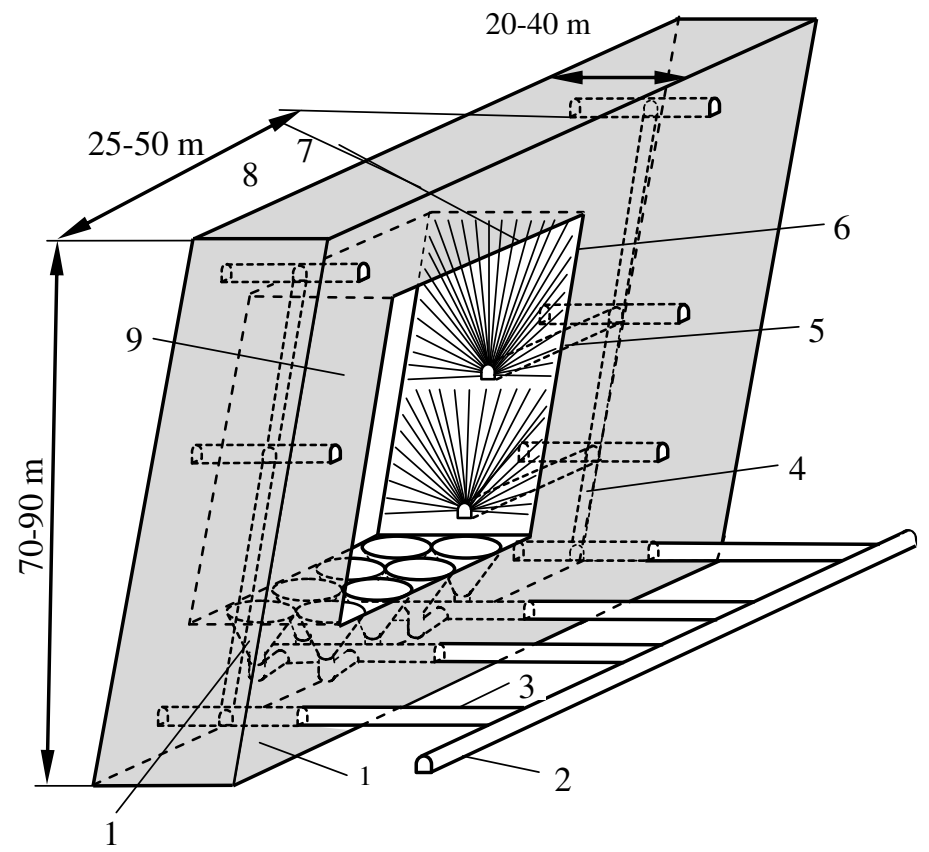

Fig. 3. The scheme of construction of the mining block 
The structural and technological parameters of all these elements must be determined by appropriate calculations and justified by a number of factors, namely: geological (by geological structure of a particular excavation site), hydrogeological (by nature of the watering of the array); geomechanical (by parameters of action of mountain pressure, presence of tectonic disturbances, presence of zones of weakening of rocks); technological (on necessary extraction of ore, on technologies of performance of different processes on preparation and refining of ore, on technological connections and dependencies between different processes of development; the rate of profitability of production.

\section{Algorithm for system object-oriented modeling and design of technological schemes for mining reserves of mining blocks.To} solve this problem, the authors propose the development based on the principle of systematic object-oriented modeling and design of technological schemes for mining reserves of extractive blocks (SOOMAD), which implements the approaches and means of the problem- and object-oriented and system design $[9,10]$.

The essence of SOOMAD is to solve the problems of designing mining and technological objects with mutual technological and parametric harmonization of all their structural elements, taking into account their role and share in the formation of technical and economic characteristics of the final production of the mining company, implementation of forecasting, planning and control of project parameters. production facilities during their complete life cycle, which makes it possible to take into account the instability of the design objects parameters in the period of their construction and production activities, which is limited by the natural lifecycle of objects (2-5 years depending on their size).

The implementation of this approach should be carried out according to the algorithm shown in (Fig. 2). 


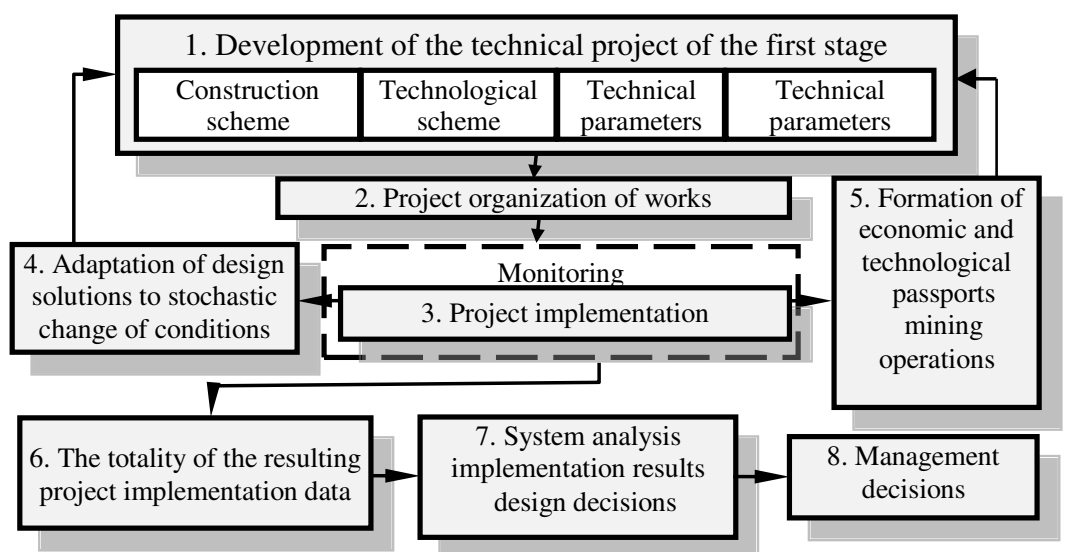

Fig. 4. SOOMAD implementation algorithm

This algorithm includes the following steps:

1. Development of a technical project of a mining and technological object (mining block) according to the theoretical methods (block 1). To prepare the project, economic and mathematical models of several technically acceptable variants of the scheme of the object are formed, their technical parameters are calculated, an economic model is being constructed, the forecast economic characteristics are determined, the timeframe and stages of the project realization are calculated. From these options, the best option is chosen based on the feasibility assessment of the specific system of proposed indicators (described below). Based on this variant the technical design of the block of the first stage is developed.

2. Development of a technical project of a mining and technological object (mining block) according to the theoretical methods (block 1). To prepare the project, economic and mathematical models of several technically acceptable variants of the scheme of the object are formed, their technical parameters are calculated, an economic model is being constructed, the forecast economic characteristics are determined, the timeframe and stages of the project realization are calculated. From these options, the best option is chosen based on the feasibility assessment of the specific system of proposed indicators (described below). Based on this variant, the technical design of the block of the first stage is developed. 
3. According to the technical design, the preparation of the project organization of work (POW) (block 2), which develops organizational measures for the construction of a specific unit and the implementation of its basic production functions.

4. After approval of the first stage project, the process of its implementation begins (block 3). Technical and economic monitoring is carried out during the implementation.

5. In the process of project implementation at certain stages, based on monitoring data, an additional adaptation of the already designed scheme of the facility to the actual mining conditions is performed (block 4), since the first stage project is developed on new data on the conditions of implementation of development, which are largely probable. the complexity and imperfection of modern methods of geological prospecting at great depths [8]. The input data for this adaptation is obtained through operational exploration and feasibility monitoring, which establishes:

6. the actual technical and economic characteristics of the facility and its construction conditions; the degree of deviation of the actual geotechnical conditions of its functioning from the design values;

7. deviation of actual object parameters from design. In addition, the actual parameters of resource consumption during the construction and operation of the facility are set.

8. Precise technical and economic data bases (block 5) are formed on this basis. These data are hereinafter accepted as standards and used for further economic-mathematical modeling of such objects.

9. Adaptation of the first stage project to the scale of changes in the project leads to the development of the second stage project directly in the process of practical implementation of the first stage project. Such changes, while maintaining the overall concept of the first stage project, can significantly alter the design and parametric characteristics of the design object with the corresponding changes in the economic results of its operation. These results also need to be forecasted in the second stage of design, choosing options for local solutions based on their predictive performance, that is, the modeling process extends throughout the life of the design object.

10. After completion of the project, the final technical and economic characteristics (block 6) are calculated as a result of the accumulation and analysis of information in the monitoring process. The 
obtained data are analyzed (block 7) to determine the actual performance of the object and the magnitude of its deviation from the design and identify the reasons for these deviations.

11. According to the results of the analysis, management decisions (block 8) are made to improve the production activity of the enterprise, the methodological basis of the design process and its information and regulatory framework.

12. One of the main elements in the above algorithm is to determine the number of financial costs required to implement specific design decisions. Based on the calculation of the forecast value of this parameter, the economic effectiveness of the decisions is determined and substantiated, the economic feasibility (or impracticality of their implementation) and many technical and economic indicators characterizing the efficiency of the development are calculated.

4. Mathematical model. To ensure the accuracy of the values of these indicators, the modeling system of mining and technological objects should make economic calculations on the basis of the proposed special logic and mathematical model, which relates the geotechnical conditions of construction and operation of objects and their parameters with the characteristics of resource consumption and economic results of implementation. This model is described by this logic-mathematical function

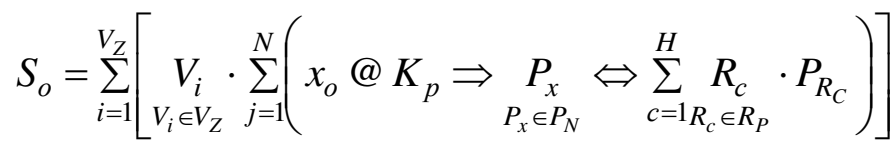

According to this function, the amount of financial costs $S_{\mathrm{o}}$ for the implementation of a project decision of a particular object is defined as the sum of the outputs of the volumes of $V_{i}$ specific types of mining $i$ of all their species $V_{Z}$, regulated by this scheme, for the sum of the output of the specific costs of resources of the species $R_{c}$ from all kinds of resources $R_{P}$, identified (as equivalent to $\Leftrightarrow$ ) the decision taken $P_{x}$, at its current price $P_{R c}$.

Decision Px presenting economic and technological passport (ETP) each specific elementary mining-technological object, from which the scheme of the projected object is formed. This ETP is selected from the set $P_{N}$ all possible passports, according to this type 
of site of the object of design and the corresponding process in the general scheme of mining $\left(P_{x} \in P_{N}\right)$.

Decision Px is an implication (conclusion $\Rightarrow$ ) operations of logical relation@ between the selection key xo, which describes the specific mining conditions and the criterion $K_{p}$, which describes the conditions of use of each ETP of the respective object.

Economic and technological passport represents a new concept in the field of modeling of mining and technological objects. ETPs are developed in the form of a structured electronic document that reflects the technical and technological solutions, as well as the conditions for the use of elementary mining and technological objects - stripping, preparatory, threaded and other technological work and performing all types of mining operations. In addition, the ETP is used as a software to calculate the unit cost of resources and their value (at current market prices) per unit of output that results from the execution of specific types of mining, namely: the cost of extraction of $1.0 \mathrm{~m} 3$ of rock in the workings, drilling of 1.0 linear meter of wells, 1.0 linear meter of drill holes in drilling operations, 1.0 ton of production and delivery of ore from the clearing space, etc.

Construction of models of the structure of large mining and technological objects on the basis of complexes of ETP allows to change at any time local and global technical and technological decisions (schemes, technology, parameters), input data (resource consumption, specific volumes of expenses of specific types of resources, prices for resources), quickly calculate the predicted technical and economic characteristics of objects and final products in the implementation of a specific variant of technical and technological solutions to the above-described logic and mathematical function.

Economic and mathematical models, the structure of which is formed on the basis of the ETP, allow to follow the dynamics of changes in the technical and economic characteristics of objects, that is, to simulate the process of realization of projects, due to the gradual formation of their structure, in accordance with the volumes and types of works by stages of construction and gradual functioning of the object. This allows taking into account the dynamics of expenditures 
of resources and financial resources, which is important for accurate planning of production activity of a mining enterprise.

The formation of the ETP is based on the actual data of elementary mining and technological objects obtained through objectoriented technical and economic monitoring of the implementation of previously designed objects that are used in this project, which ensures high reliability of the data. These data form the regulatory information base for design modeling of new production facilities using the direct calculation method (rather than the statistical modeling currently used [6]).

One of the most important issues in the design of mining and technological facilities is the correct assessment of the technical and economic efficiency of their design solutions, which underlies the optimization of production.

At present, such an assessment is carried out on the direct characteristics of the objects themselves according to their types, that is, according to the schemes of disclosure, schemes of preparation and cutting of stocks, technological schemes of sewage extraction. This approach is not correct and often leads to poor decisions. For example, when designing a technological scheme for the treatment of extraction, a certain solution at the level of performance of a particular mining unit is effective, but taking into account the factors that operate in the processing of ore into commodity iron ore products, these decisions may lead to low production efficiency. This situation is due to the fact that the final technical and economic characteristics of the products are affected not only by the internal characteristics of the adopted design decision but also by the features of all other processes that are performed to obtain the product. At the same time, the characteristics of all these processes can be in some way interdependent and have both a positive and a negative impact on the end result of mining.

Thus, the correct estimation of design decisions of specific mining and technological objects should be carried out only on the final results of development, ie commodity iron ore products. This approach causes a systematic design. For example, when the high productivity of ore extraction and its entry into the system of its processing into a commodity product, which is a positive factor for the economy of the operation of a particular unit can lead to increased 
losses of hematite during its processing into a commodity product. In this way, the performance of the unit and the performance of the ore processing must be consistent, and this should be foreseen by the project itself for the refinement of each specific mining unit.

The authors have developed a system of assessment of design mining and technological solutions, the basis of which is the technical and economic indicators, the values of which are calculated according to the economic and mathematical models below.

These metrics include: the total financial cost of building and operating the facility $C_{t}$; the quantity of ore that will be obtained during its operation $Q_{o}$, or with the use of this facility (when designing disclosure schemes, preparation and slicing); projected balance profit from the sale of $P_{r}$ ore; total cost of commodity ore $C_{t}$; efficiency of financial investments in construction and operation of the projected object $F$; ore loss ratios of the balance sheet $k$; clogging factor of the ore extracted kcf at its extraction; loss of quality of the extracted ore $\Delta C$ compared to the quality of the ore balance sheet; coefficient of removal of commodity product from the subsoil $K_{r}$; coefficient of compensation for financial loss from ore losses $K_{c}$; specific mine costs $M C_{\mathrm{s}}$; the cost of extracting commercial ore from the subsoil $C_{s}$; the specific cost of building the facility $C_{b}$; technical efficiency of financial investments in the construction and operation of the facility $E_{e f}$, a level of economic efficiency of exploitation of the natural stock of commodity product $E_{m n}$.

The effectiveness of design decisions is based on this approach. There are two major economic factors that reflect and limit the level of technical and economic efficiency of development, namely: the number of financial costs for the production of commodity ore $\Sigma C_{c o}$ and cost-effectivity of development investments $P$. These indicators are related to the profit generated from the sale of commodity ore $P_{c o}$ and the regulatory costeffectiveness of development $P_{n},(14 \ldots 15 \%)$ this relation

$$
P=\frac{100 P_{c o}}{\sum C_{c o}} \geq P_{n}, \%
$$

Value $P_{c o}$, planned by the amount of necessary financial costs of enterprises to ensure the necessary economic efficiency of production. This makes it possible to calculate the predictive value of profits $P_{i}$, which must be obtained when the particular projected object is functioning 


$$
P_{i}=\frac{P_{c o} B_{i} C_{b}}{\sum B_{j} C_{c j}} \geq P_{n}, \%
$$

where $B_{i}$ - ore balance will using this facility (opening, preparation and slicing schemes, refining), thousand tons; $I_{k}$ - the iron content of the ore balance sheet, $\% ; \Sigma\left(B_{j} \cdot C_{j}\right)$ - total metal reserves in the ore of all $\mathrm{j}$ blocks, scheduled for completion within a specified time, thousand tons, with metal content in the ore of each block $C_{b}, \%$, which is part of the field operated under the floor plan.

From expression (2), we derive a mathematical model for complex evaluation of the development efficiency.

$$
P=\frac{100 \cdot K_{f} \cdot \frac{100-k_{e}}{100-k_{l}} k_{e m} B \cdot\left[P_{m}-\frac{\sum C_{o e}+K_{n} \frac{100-k_{e}}{100-k_{l}} k_{e m} \cdot B \cdot S_{t}}{K_{n} \cdot \frac{100-k_{s}}{100-k_{c f}} k_{o t} \cdot B}\right]}{\sum C_{o e}+K_{n} \cdot \frac{100-k_{e}}{100-k_{l}} \cdot k_{e m} \cdot B \cdot S_{t}} \geq P_{n}
$$

where $k_{e m}$ - output coefficient of commodity ore from the ore mass, which will be obtained upon realization of this project, $\mathrm{UAH} ; K_{f}-$ conversion factor of thousand tons in tons. $k_{l}$ - predicted (or normative) value of the ore loss factor that will be obtained when the field site is being mined for this project, $\% ; k_{l}$ - clogging factor, $\%$; $P_{m}-$ contractual (market) price of 1 ton of commodity ore, UAH/ton; $\Sigma C_{o e}$ - costs for ore extraction for this project are determined by the expression modeling method (1), thousand UAH.

In formula (4), particular attention should be paid to the expression $\left(100-k_{e} / 100-k_{l}\right)$. This expression is recognized as the value of the so-called coefficient of visible extraction of the $K_{v v}$. The particular importance of this coefficient is due to the fact that the volume of the extracted ore extracted from a certain volume of the balance reserve of ore B depends on its value. This value depends on two indices $k_{l}$ and $k_{c f}$ ). Considering that at present the value of technological losses of ore at domestic iron ore mines are high enough and make $k_{e}=9$ $20 \%$ by weight, $k_{l}=7-18 \%$, this has a very negative impact on the economic results of development. For these reasons, up to $20-25 \%$ of the value represented by the ore balance sheet is lost at domestic mines, which is a very significant problem. Therefore, when designing the forecasting values of $k_{e}$ and $k_{l}$, special attention should 
be paid. For this purpose, special techniques have been developed for modeling technological schemes of soldering of reserves of extractive blocks, according to which it is possible to fulfil such forecast and indicators $k_{e}$ and $k_{l}$ are one of the main criteria for the choice of rational development systems for specific conditions of its implementation [11].

The $k_{l m}$ value is calculated according to the condition $k_{l m}=k_{c} \cdot k_{f}$, where $k_{c}$ - depends on the allowable difference $\Delta C_{n}$ between the iron content of the ore extracted $C_{l}$ and its content in commodity ore $C_{m}$, $\% ; k_{f}$ - depends on the strength factor of the ore $f(f=0,1-30)$

$$
\begin{gathered}
k_{c}=\exp \left[\left(426,3 \Delta C+16,7 e^{\Delta C_{n}}\right) \cdot 10^{-6}+9,4 \cdot 10^{-3} \Delta C_{n}-0,01\right] \\
k_{f}=\exp \left[-3,3767 \cdot 10^{-6} \cdot \exp (f)\right]
\end{gathered}
$$

Specific mine costs of $S_{t}$ are determined by the costs of construction of the disclosure schemes $\mathrm{C}_{s}$ and preparing $C_{p r}$, the rates of depreciation of the openings $k_{a p}$ and preparing $k_{a n}$; costs for their operation, respectively, $C_{e p}$, $C_{e n}$; maintenance costs of department services $\mathrm{C}_{\partial}, . U A H /$ ton

$$
M C_{c}=\sum C_{t} / Q_{m p t}=\left\lfloor\left(C_{s} \cdot k_{a p}+C_{e p}\right)+\left(C_{p r} \cdot k_{a n}+C_{e n}\right)+C_{\partial}\right] / Q_{m p t},
$$

where $Q_{m p t}$ - a quantity of commodity ore, realized within the specified period, thousand tons.

The main difficulty in assessing the effectiveness of design mining and technological solutions is to determine the amount of financial costs for the following mining operations: construction workings opening $C_{s}$, preparing $C_{\mathrm{pr}}$, and for the extraction of ore $\Sigma C_{t}$, which includes mining and cleaning works (blasting, ore production and delivery). The amount of these costs depends on the specific design and technological decisions of the projected objects. These values can be determined by economically and mathematically modeling their circuits by function (1) and verifying that such a constraint is satisfied

$$
\Sigma C_{t} \leq k_{l m} \cdot D \cdot\left(S_{m p}-S_{t}\right)
$$

where $D$ - mined ore, thousand tons; $C_{p}$ - the permissible cost of commodity ore;

$$
S_{m p}=\left(K_{n} \cdot Q_{m p} \cdot P_{r o}-P_{c o}\right) / K_{n} \cdot Q_{m p} .
$$


The difference $\left(S_{m p}-C_{t}\right)$ determines the permissible cost price of $C_{a}$ of a commodity product contained in a specific volume of ore balance sheet) and is part of the extracted ore mass $Q_{m p}=k_{l m} \cdot D$.

$$
S_{a m p}=S_{m p}-C_{t} \text {. }
$$

The ratio between the values $S_{a m p}$ and $\Sigma C_{o e}$ form the basis for the normalization of ore extraction rates by the criteria of economic efficiency of mining a specific mining block, due to their relationship with the value of the coefficient of visible ore extraction $K_{v e}$

$$
\frac{C_{o e}}{K_{n} \cdot B \cdot k_{e m} \cdot S_{\text {omm }}}=K_{v e}=\frac{100-k_{e}}{100-k_{l}} .
$$

Normative value $k_{1}$ can be defined by from the allowable loss of quality of the balance stock in the extraction of ore $\Delta C_{p}=C_{b}-C_{\min }, \%$. From here $k_{l}=\Delta C_{p} /\left(C_{b}-C_{a}\right)$, where $C_{a}$ - is the average iron content of the ore clogging rocks, $\%$. Thereby, the normative meaning $k_{\mathrm{n}}$ can be defined by the expression, $\%$

$$
k_{n}=1-\left[\left(1-k_{l}\right) \cdot \Sigma C_{o e} /\left(K_{n} \cdot B \cdot k_{l m} \cdot S_{o m p}\right)\right] .
$$

The following indicators are calculated:

Loss compensation factor $K_{c f}$ for the loss from the loss of commercial ore. This indicator determines the degree of compensation for the profit received from the implementation of the project decision, the amount of financial loss from the inevitable technological losses of ore, $\$$ units

$$
K_{c f}=\frac{100 \cdot P_{c o} \cdot\left(100-k_{e}\right)}{P_{r o} \cdot k_{l m} \cdot B \cdot\left(100-k_{l}\right)},
$$

The unit construction costs of the facility are projected taking into account the ratio (14). This indicator reflects $S_{c}$ in financial terms, the level of structural and technological complexity of the mining and technological object, as well as the construction conditions for a particular variant of its design decision. The necessity of its definition is caused by the fact that mining and construction works are one of the most resource-intensive and costly works.

$$
S_{c}=\frac{C_{r}+C_{p}+C_{t}+C_{t w}}{B \cdot \frac{100-k_{e}}{100-k_{l}} \cdot k_{e m}}=\frac{\sum_{i=1}^{4} \sum_{j=1}^{M}\left[L_{i j} S_{i j}\left(C_{B P D i j}+C_{\kappa i j}+C_{o i j}\right)\right]}{B \cdot \frac{100-k_{e}}{100-k_{l}} \cdot k_{e m}},
$$


where $C_{r}, C_{p}, C_{t}, C_{t w}$ - costs for conducting and equipment, respectively: revealing, preparatory, threaded, technological workings, are determined by function (1), thousand UAH.; $i$ - work type identifier; $j$ - i production site identifier with specific geotechnical conditions; $M$ - number of plots; $L_{i j}$ - working length of the $i$-th species in the $j$-th plots; $S_{i j}$ - a cross-section of production; $C_{B P D}, C_{\kappa}, C_{o}$, - specific costs, respectively, for the implementation of the $\mathrm{BPD}$, mounting, the equipment production side of the appropriate type, are determined by the selected ETP, in accordance with the conditions of development and the required characteristics of workings, UAH/t.

When evaluating the design of mining blocks, this indicator is an alternative to the indicator "costs of pre-cut work per 1000 tons of balance sheet", which is currently widely used to compare the options of block schemes, but from an economic point of view, it is incorrect because takes into account the individual characteristics of the workings, which differ significantly in different types of workings.

The technical and economic efficiency of financial investments is determined by the amount of commodity ore that will be received per unit of investment in the implementation of a specific project decision. This indicator is one of the most important and reflects how, from a technical point of view, the financial resources invested in the construction and operation of this facility will be used by the amount of commodity ore received per unit of these funds.

$$
E_{e e}=\frac{1}{S_{o m p}+C_{t}}=\frac{B \cdot k_{e m} \cdot\left(100-k_{e}\right) /\left(100-k_{l}\right)}{\Sigma C_{o e}+K_{n} \cdot B \cdot \frac{100-k_{e}}{100-k_{l}} \cdot k_{e m} \cdot C_{t}}
$$

The level of economic efficiency of the exploitation of the natural stock of commodity ore, determines how economically efficient was extracted and part of the ore $Q_{m p}^{\prime}$, determines how economically efficient was extracted and the part of the ore which in the natural state (in the balance reserve) met the requirements for commodity production. This figure is calculated as the ratio of estimated profit from the sale of commodity ore $P_{\mathrm{i}}$ to that part of the ore balance sheet $B_{i}$, which has a metal content equal to that of commodity ore. It is taken into account that the profit will be obtained also from that part of commodity ore which will get into ore mass with impurities of 
other breeds, and also that in the balance stock the metal content $C_{b}$ can be equal to commodity $\mathrm{C}_{b}=C_{c}$, or less $C_{b}<C_{c}$, or more $C_{b}>C_{c}$.

$$
E_{e}=\frac{P_{i}}{Q_{c}^{\prime}}=\frac{Q_{m p} \cdot P_{r o}-\sum S_{m p}\left(100-k_{e}\right)}{B_{i}\left(C_{b} / C_{c}\right)\left(100-k_{l}\right)} .
$$

where $Q_{c}^{\prime}$ - commodity ore, which was contained in the redeemed balance sheets, tons.

The technical efficiency of the exploitation of the industrial ore stock should be estimated by the coefficient of extraction from the bowels of commercial ore $K_{b c o}$. This figure reflects the amount of commodity ore that will be received from a given site of the deposit, compared to the amount of ore contained in the natural balance stock and meets the consumer's requirements for the commodity product.

$$
K_{d c o}=\frac{B_{i} \cdot\left(C_{b} / C_{m p}\right)}{Q_{m p}}=\frac{B_{i} \cdot\left(C_{b} / C_{m p}\right)}{K_{n} \cdot B \cdot \frac{100-k_{e}}{100-k_{l}} \cdot k_{e m}} .
$$

In the aggregate, all of the indicators described reflecting the effectiveness of the design decision of a particular mining and technological object in sufficient volume to substantiate the feasibility (or impracticality) of its selection and implementation in practice, especially when comparing complex construction and structure and technology of objects. Sufficiency of the described descriptions of the interests SOOMAD implemented by the authors of the automated system of the "Geotechnologist " project. The elements of the system have passed approbation in a number of mines of the Krivorizhsky Zalizruznogo pool. In the second house, a number of important project-related mining-technological tasks were solved, and the following: the optimal scheme for the preparation of a family home at the field of Ternivsk PJSC «Krivbaszalizrudcom» block was completed, the experimental project of a 149-154 in the minds of the "Zhovtneva» mine of OJSC KZHRK; the optimum geometric parameters of the structural elements of the view blocks at the Yuvleyna mine and the PJSC "Suha Balka" mine are marked; The optimal technological scheme for the production of the "Golovna" mine of the "Yuvileyna" mine was formed.

Today, a more advanced data system and software development support for the model of high-tech elements of industrial circuits and 
additional mine and technological systems of mines for expanding the number of design tasks are needed.

5. Conclusion. Based on the above materials, we can draw the following conclusions:

The problem of selection, implementation in practice and determining the actual effectiveness of design solutions for the development of reserves of extractive blocks, which represent the main production facilities of mines, and is currently one of the most important, complex and not yet fully resolved the field of underground mining of rich ores in difficult mining-technical and economic conditions.

The need to solve this problem requires the development of methodology, methods and specialized tools for modeling and designing structures and technological schemes for the development of block reserves, which would allow to select and substantiate the technical and economic efficiency of development solutions at the systemic level of production at underground iron-ore mining.

To solve this problem, the authors have developed a system of computer simulation and design of the process of working off the belts of mining blocks, in a methodological basis and the concept of which laid an approach to considering each mining block as an element of a complex and branched production and technological system of the mine, which is unique in terms of working out its stock and parameters, has a clear life cycle, stage of implementation. The efficiency of this process can be correctly evaluated only by the parameters of the final iron ore product, which will be produced from the block ore reserve with its specific parameters (volume, natural quality of the ore, geological and mining conditions of occurrence and mining of the reserve).

The authors have developed an algorithm for modeling technological schemes of mining reserves of extractive blocks, the procedure for the development and use of technical and economic passports of elements of block structures, from which the variants of technological schemes of working out of their reserves are formed and the choice of the optimal option is determined, the technical and economic characteristics of its implementation are determined and substantiated. developed a special system for economic evaluation of the effectiveness of the application of technological and logical 
schemes of development and economic and mathematical models to determine values of economic indicators that make up the system.

Further development of the developed systems of modeling and designing is the expansion of its software to solve more specific problems of modeling of block elements and their technological schemes and their design, expansion of the base of technical and economic passports of elements of technological schemes of working out of stocks of blocks and development of graph analytic subsystem of support for mining of production blocks. , which provides a large amount of input data for the economic and mathematical modeling of block structures and technological schemes of working out their reserves.

\section{References}

1. Popov S.O., Babets E.K., Kolosov V.A., Rudko G.I. State and prospects of development of the iron ore industry of Ukraine. tax collector Kryvyi Rih: RMI SHEI «KNU», 2015. №55. P. 12-36.

2. National program of development of mineral resources of Ukraine for the period up to 2030/ Approved by the Law of Ukraine of April 21, 2011. №3268-VI [Electronic resource]. URL: http: // zakon2.rada. gov.ua/laws/ show/3268-17.

3. Bovin A.A., Kurlenya M.V., Shemyakin E.I.Problems of development of mineral deposits at great depths // Physical and technical problems of mining, 1983. № 3. - P. 64.

4. Prilipenko E.D. On the ratio of underground and open methods for developing iron ore deposits in Ukraine / Improving mining production. - Kryvyi Rih: RMI, 1990. P.25-28.

5. Imenitov V.R. Technology and organization of production processes in underground mining of ore deposits M.: Nedra, 1973. 270 p.

6. Utkina S.I. Mining Enterprise Economics Edition: Publishing House of the Moscow State Mining University, Moscow, 2003, 262 p., ISBN: 5-7418-0226-5.

7. Baranov A.O. Design of technological schemes and processes of underground ore mining. M .: Nedra, $1993.273 \mathrm{p}$.

8. Chernenko A.R., Grigoriev A.P., Dyadechkin N.I., Kononov I.P. Underground mining systems of the Kryvyi Rih basin. Typical passports. - Kryvyi Rih, RMI, 1986. 133 p.

9. Shek V.M. Object-oriented modeling of mining systems. M.: MGU, 2000. 304 p.

10. The principles of system design [Electronic resource]. URL: https://helpiks.org/7-84686.html.

11. Instructions for rationing ore extraction indicators by technical, technological and economic criteria, their forecasting and accounting in the process of underground mining of iron ore deposits / Azaryan A.A., Kolosov V.A., Morgun A.V., Popov S.O., Stupnik N.I. - Kryvyi Rih: Oktan-print, 2012.178 p. 